\title{
EFEITO DA ADUBAÇÃO NITROGENADA SOBRE A PRODUÇÃO E QUALIDADE DE SEMENTES DE ALFACE \\ (Lactuca sativa L.)
}

JOSÉ LENILTON DE (ARVALHO

Engenheiro-Agrönomo

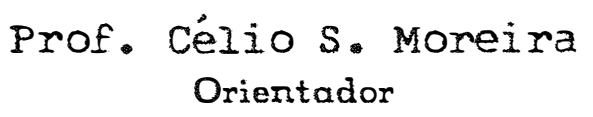

Orientador

Dissertaçāo apresentada à Escola Superior de Agricultura "Luiz de Queiroz", da Universidade de São Paulo, para obiençāo do titulo de Mestre em Fitotecnia.

\footnotetext{
$P|R A C| \subset A B A$

Estado de São Paulo - Brasil

Março, 1978
} 
ii。

\author{
HOMENAGEN \\ Aos meus pais \\ Aos meus sogros \\ Aos meus irmãos
}

A minha esposa

ZILDA

$e$ aos meus dois filhos

FABIO ROMERO E KALINA LICIA

com carinho,

DEDICO 


\section{AGRADECIMENTOS}

Ao Profassor Dr. Keigo Minami, a cuja orientacão devemos este tra balho:

Aos Professores Dr. Francisco Ferraz de Toledo, Dr. Paulo Haag,Dr. Jülio Marcos Filho, pelas sugestöes e oportunas críticas;

Aos Colegas Amariles Santos Dias, Clidenor Dantas de Oliveira, Iva nildo Muniz Santiago e José Pires Dantas, pelos incentivos e apoio recebidos durante o curso:

Ao Colega João Riboldi, do Departamento Agro-Zootécnico do CCT/ UFPb; pela permanente orientação estatística:

A Srta. Maria Elisabeth de Carvalho, Bibliotecäria da ESALח, pela ordenação das referências bibliogräficas:

A Escola Superior de Agricultura "Luiz de Dueiroz", pela oportunidade de realização do curso de pós-graduação;

A Universidade Foderal da Parafba, pela oportunidade concedida e ao Programa de Ensino Agrícola Superior - PEAS, pela ajuda financeira durante a realização do curso:

A todos os Professores que ajudaram na minha formação;

Aos Funcionários do Setor de Horticultura, pela ajuda na condução dos experimentos de campo:

A todos que, direta ou indiretamente, contribuiram para que o pre sente trabalino fosse realizado. 


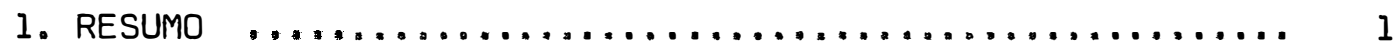

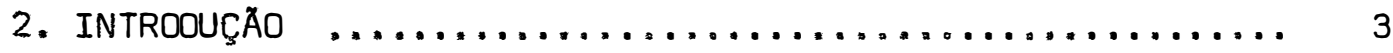

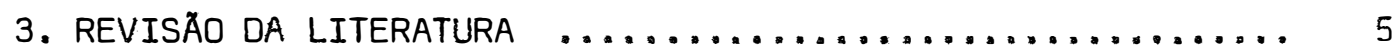

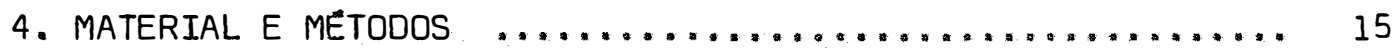

4.1 - Instalação do Ensaio $\ldots \ldots \ldots \ldots \ldots \ldots \ldots \ldots \ldots . . \ldots \ldots$

4.2 - Testes Preliminares $\ldots \ldots \ldots \ldots \ldots \ldots \ldots \ldots \ldots \ldots \ldots \ldots$

4.3 - Testes de Laboratório ...................... 19

4.3 .1 - Germinação ........................... 19

4.3.2 - Primeira contagem de germinação ......... 20

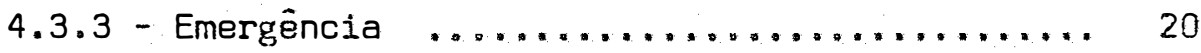

4.3 .4 - Peso de 1000 sementes ............... 21

4.3 .5 - Determinação de umidade $\ldots \ldots \ldots \ldots \ldots \ldots .21$

4.4 - Análise Química das Sementes $\ldots \ldots \ldots \ldots \ldots \ldots \ldots .22$

4.5 - Estudos de Campo ........................ 22

4.5 .1 - Determinação da matéría seca das plantas .. 23

4.5 .2 - Determinação do peso da matéría fresca das plantas .......................... 23

4.6 - Método estatístico ....................... 23

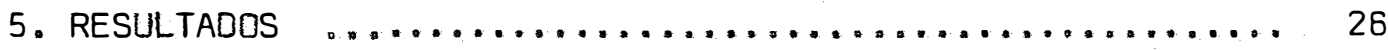

5.1 - Produção de Sementes ...................... $2 E$

5.2 - Testes Preliminares $\ldots \ldots \ldots \ldots \ldots \ldots \ldots \ldots \ldots . .27$

5.3 - Testes de Laboratório ........................... 27 
Pág.

5.3 .1 - Germinação $\ldots \ldots \ldots \ldots \ldots \ldots \ldots \ldots \ldots \ldots \ldots \ldots \ldots$

5.3 .2 - Primeira contagem de germinação ........ 28

5.3 .3 - Emergēncia $\ldots \ldots \ldots \ldots \ldots \ldots \ldots \ldots \ldots \ldots \ldots \ldots . \ldots \ldots$

5.3 .4 - Peso de 1000 sementes $\ldots \ldots \ldots \ldots \ldots \ldots$.............. 30

5.3 .5 - Determinação de umidade $\ldots \ldots \ldots \ldots \ldots \ldots$......... 31

5.4 - Anälise Química das Sementes ............... 32

5.4 .1 - Determinação de nitrogênio $\ldots \ldots \ldots \ldots \ldots \ldots . \ldots 32$

5.4 .2 - Determinação de fósforo $\ldots \ldots \ldots \ldots 33$

5.4 .3 - Determinação de potássio $\ldots \ldots \ldots \ldots \ldots \ldots$

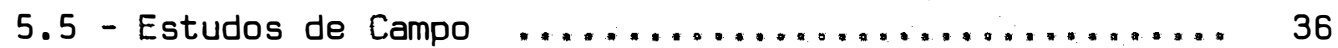

5.5 .1 - Determinação da matéria seca das plantas .. 36

5.5 .2 - Determinação do peso da matéria fresca das plantas ........................ 37

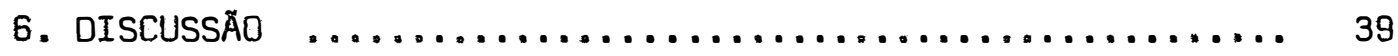

6.1 - Produção de Sementes $\ldots \ldots \ldots \ldots \ldots \ldots \ldots \ldots \ldots . \ldots \ldots$

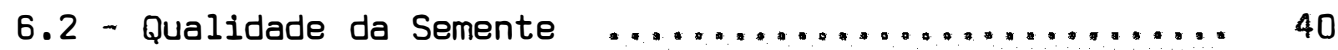

6.2 .1 - Teste de germinação $\ldots \ldots \ldots \ldots \ldots \ldots \ldots 40$

6.2 .2 - Testes de vigor ......................4 41

6.2.2.1 - Primeira contagem de germinação .. 41

6.2 .2 .2 - Emergência $\ldots \ldots \ldots \ldots \ldots \ldots . \ldots . \ldots 4$

6.2 .3 - Peso de 1000 sementes $\ldots \ldots \ldots \ldots \ldots \ldots \ldots \ldots$......... 43

6.3 - Análise Química das Sementes .......................... 44 
vi.

Pág。

6.4 - Estudos de Campo .......................... 44

6.4 .1 - Determinação da matérla seca das plantas .. 44

6.4 .2 - Determinação do peso da matéría fresca das plantas ........................... 45

7. CONCLUSÕES $\ldots \ldots \ldots \ldots \ldots \ldots \ldots \ldots \ldots \ldots \ldots \ldots \ldots \ldots \ldots \ldots$

8. SUMMARY $\ldots \ldots \ldots \ldots \ldots \ldots \ldots \ldots \ldots \ldots \ldots \ldots \ldots \ldots \ldots \ldots \ldots \ldots$

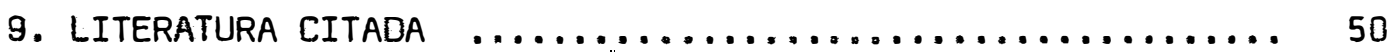




\section{LISTA DE QUADROS}

QUADRO

Pảg.

I Características químicas do solo da área experimenta

2 Quantidades de sulfato de amónio usadas nos tratamen tos do experimento $\ldots \ldots \ldots \ldots \ldots \ldots \ldots \ldots \ldots$

3 Esquema utilizado para anälise de variância emprega do nas determinações de $N, P, K$ e determinações re-

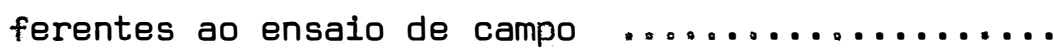

4 Esquema utilizado para análise de variância, empregado nas quatro épocas da velocidade e porcentagem de emergência, peso de 1000 sementes, porcentagem de germinação e primeira contagem de germinação ... 24

5 Produção de sementes. Resultados obtidos nas quatro repetiçōes (em gramas/parcela) ............. 26

6 Teor de umidade, porcentagem de pureza e germinação

7 Germinação. Resultados obtidos nas quatro épocas $(x=\operatorname{arc} \operatorname{sen} \sqrt{\%}) \quad \ldots \ldots \ldots \ldots \ldots \ldots \ldots \ldots \ldots . \ldots \ldots . \ldots \ldots$

8 Vigor: Primeira contagem de germinação. Resultados obtidos nas quatro épocas $(x=$ arc sen $\sqrt{\%}) \ldots 28$

9 Vigor: Velocidade de emergência. Resultados obtidos nas quatro épocas ( $x$ = índice de velocidade de emer

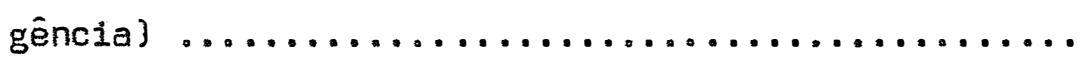


viii.

QUADRO

Pág.

10 Vigor: Porcentagem de emergência. Resultados obtidos nas quatro épocas $(x=\operatorname{arc} \operatorname{sen} \sqrt{\%}) \ldots . . . . .30$

11 Peso de 1000 sementes. Resultados obtidos nas quatro épocas (em gramas/tratamento) .............. 31

12 Umidade das sementes armazenadas em câmara seca nas quatro épocas. Médias de duas repetições $(\%) \ldots 32$

13 Determinação de nitrogênio. Resultados obtidos nas

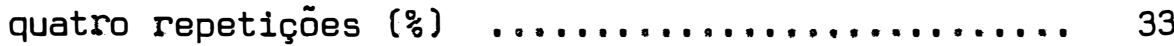

14 Determinação de nitrogênio. Resultados obtidos nas quatro repetições $(x=$ arc sen $\sqrt{\%}) \ldots \ldots \ldots . \ldots . . .33$

15 Determinação de fósforo. Resultados obtidos nas qua

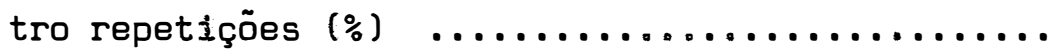

16 Determinação de fósforo. Resultados obtidos nas qua tro repetições $(x=\operatorname{arc} \operatorname{sen} \sqrt{\%}) \ldots \ldots \ldots \ldots \ldots \ldots . \ldots . \ldots 34$

17 Determinação de potássio. Resultados obtidos nas

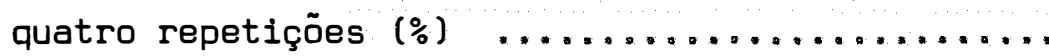

10 Determinação de potássio. Resultados obtidos nas quatro repetições $(x=\operatorname{arc} \operatorname{sen} \sqrt{\%}) \ldots \ldots . \ldots . . . . . . .36$

19 Determinação de matéria seca. Resultados obtidos nas quatro repetições dos diversos tratamentos (em gra-

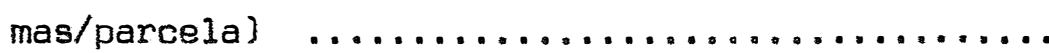


QUADRO

Pág.

20 Produção de matéria fresca. Resultados médios obt1dos nas quatro repetições dos diversos tratamentos (em gramas/parcela) 
1. RESUMO

0 presente trabalho, conduzido nos campos experimentais do Departamento de Agricultura \& Horticultura da Escola Superior de Agricultura "Lu1z de Quelroz", da Universidade de São Paulo e no Laboratório de Sementes, pertencente ao mesmo Departamento, vi. sou avaliar o efeito da adubação nitrogenada sobre a produção e qua lidade de sementes de alface (Lactuca sativa L.). Ut1lizou-se semen tes da cultivar Gorga. Os tratamentos usados foram $0,10,20$ e 40 gramas de $\mathrm{N}$ por $\mathrm{m}^{2}$.

As sementes foram armazenadas em câmara seca $123^{\circ} \mathrm{C}$ e 35\% UR) durante 7 meses. Durante esse período, foram realizados, em 4 épocas com Intervalos bimestrais, testes de germinação, primeira contagem de germinação, velocidade de emergêncla, porcentagem de emergêncla, peso de 1000 sementes e determinação do teor de umidade. 
Foram feltos estudos de campo, determinando-se o peso da matéria seca das mudas aos 30 dias após semeadas e a determ1nação do peso da matërla fresca das plantas no ponto comerclal. Para as condlçōes do experimento, chegou-se às seguintes conclusões:

a) A ałubação nitrogenada não afetou a produção e a qualidade das sementes de alface:

b) Os testes de laboratório näo foram totalmente satisfatórios para avaliar a qualidade das sementes de alface:

c) Houve uma correlaçäo positiva entre os níveis de nitrogênio e o peso das sementes, fazendo exceção o tratamento $D$ C $N f$ vel III):

d) Inicialmente houve diferenças no desenvolvimento das mudas dos diversos tratamentos;

e) As sementes da cultivar Gorga näo apresentaram dormência lo go após a sua colhelta. 


\section{INTRDDUÇAO}

Entre os fatores que influenclam a produção de uma cultura, o uso de sementes melhoradas tem um importante papel. Tecnologistas de sementes afirmam que a utilização de sementes de alta qualidade genética, em subst1tulção à comum,con tribui com aumentos ponderávels na produtividade agrícola. DELOUCHE e POTTS (1974) aflrmam que a ut1l1zação de sementes de boa qualidade pode proporcionar acréscimos de 10 a $20 \%$ na produtividade de uma determinada espécie ou cultivar.

A qualidade fisiológica de um lote de sementes, compreende uma sérle de atributos que determinam o seu valor para a se meadura e dentre eles destacam-se, segundo TOLEDO e MARCOS FILHO (1977), os seguintes: pureza varıetal, pureza física, germinação,va lor cultural, vigor, teor de umidade, presença de microorganismos, 
presença de insetos, uniformidade e peso volumétrico.

E mals frequente o uso de fertilizantes nos campos de produção de sementes do que nas lavouras de consumo (TOLEDO e MARCOS FILHO, 1977\}. Poucos trabalhos foram desenvolvidos visando veri ficar o efeito de nutrientes sobre a produção e qualidade das semen tes. As pesquisas existentes no Pals com essa finalidade, são prati camente inexistentes, de modo que a ut1lização dos fertilizantes é feita com base nos resultados obtidos para as respectivas culturas de consumo.

Devido ao exposto e à importância do assunto, o presente trabalho teve por objetivo estudar os efeltos dos diferentes níveis de nitrogênio na produção e qualidade das sementes de alface (Lactuca sativa L.). 


\section{REVISAO DA LITERATURA}

Ds nutrientes minerais estão envolvidos em todas as fases de crescimento e reprodução da planta. Um fornecimento adequa do desses nutrientes provoca o desenvolvimento normal dos tecidos reprodutivos, inicialmente pela manutenção de uma superfície foliar grande e fisiologicamente ativa que, em retorno, produz os metabóli tos e reguladores de crescimento, necessários para o desenvolvimento das flores, frutos e sementes/ KOZLOWSKI (1971), estudando o cres cimento e desenvolvimento das plantas, cita o nitrogénio como sendo o mais importante nutriente mineral para o crescimento e reprodução da planta. Sua justificativa è o fato de que, em muitas regiōes, es. pecialmente em solos arenosos, grande quantidade de nitrogênio ê per dida pela lixiviação e consequentemente faz-se necessário a sua aplicação. 
Tentando enfatizar a importância dos nutrientes sobre a produção e qualidade das sementes, DELOUCHE (1971) relatou que a fertilidade do solo e os fertilizantes aplicados, bem como as demais práticas culturais têm grande influência sobre a qualidade e a quantidade das sementes produzidas.

Ainda DELOUCHE (1972), comentando sobre os efeitos nu tricionais do solo sobre a produçäo e qualidade das sementes concluiu que, dentro de certos limites as plantas tem a capacidade de compensar, no seu rendimento e rítmo reprodutivo, as diversas deficièncias do meio ambiente: o efelto mals pronunclado da baixa ferti lidade é a menor produção. Também ressaltou que as plantas compensam as deficiências do meio ambiente, reduzindo a quantidade e não a qualidade de sementes. Mas mesmo assim. o autor referiu-se à exis. tência de trabalhos de diversos clentistas que indicaram efeitos ne gativos de deficiencias nutricionais sobre a qualidade das sementes de diversas culturas.

POPINIGIS (1974) diz que o método mais utilizado para medir a qualidade da semente é o teste de germinação. Todavia, a perda da capacidade germinativa é a última e mais desastrosa consequência do processo de perda de qualidade.

Posteriormente, TOLEDO e MARCOS FILHO (1977), fazendo referèncias ao vigor das plantas ascendentes como condição que afeta a vitalidade das sementes, destacaram que as plantas fracas geralmente produzem sementes deficientes de reservas nutritivas e 
com embriōes mal desenvolvidos.Destacaram também que é praticamente inexistente os ensaios relacionados ao uso de fartilizantes em campos de produção de sementes.

Foi ressaltado também por ALTEN e SCHULTE (1942) que o efeito dos fertilızantes pode acarretar diferenças fisiológicas em sementes de plantas geneticamente similares e que o aumento na velo cidade de germinação, causado pela adubação, pode ser devido à ação dos nutrientes sobre os enzimas da semente.

A literatura referente à influência do nitrogênio so bre a produção e qualidade das sementes de alface (Lactuca sativa $L_{0}$ ) é escassa. Devido a este fato, procurou-se reunir trabalhos de pesquisa sobre a importanncia dos nutrientes para outras hortaliças que relacionem nutrição e características das sementes.

STUART e GRIFFIN (1346), estudando a influência do ni trogênio sobre a produção de sementes de cebola, em estufa de vidro, verificaram que, com o maior nível de $N$, as plantas tiveram um desenvolvimento vegetativo acentuado, produzindo grande quantidade de bulbp̣s, mas que se obteve baixo rendimento de sementes por planta.

Já HAWTHORN (1952), estudando a interação de umidade do solo, níveis de $N$ e espaçamento, sobre a produção de sementes de cenoura, verificou que a adição de $N$ aumenta consideravelmente a pro dução de sementes. 
Procurando caracterizar a importância dos nutrientes sobre a qualidade das sementes, HARRINGTON (1960) fez referências a diversos trabalhos sobre o assunto: JAMES e BANCROFT (1951), estudando a influência dos nutrientes na qualidade das sementes do tre vo vermelho, observaram que a germinação não foi afetada pelos nIveis de nitrogênio: SCHUOEL (1952) não encontrou diferenças signifi cativas na germinação de sementes de cebola, quando produzidas em campo com ou sem adubação $N, P, K$, Ca e $S$, mas que, na produção total de sementes por ärea, houve diferenças bem significativas; PENDLETON! (1954) relatou que a adubação nitrogenada em beterraba açuca reira aumentou suficientemente a produção de sementes, assim como be neficiou a sua germinação.

EGUCHI (1960), observando o efeito do $N$ e a maneira de aplicação em repolho e couve chinesa, sobre a produção de sementes, verificou que o $N$ influi na produção de sementes e que amelhor aplicação é em cobertura e em época oportuna. Verificou também, no repolho, que a maior percentagem de sementes grandes foi encontrada no tratamento em que se obteve um maior rendimento. Contudo, não en controu diferenças significativas quanto ao peso de 1000 sementes e porcentagem de germinação.

AUSTIN (1965) analisando o comportamento das sementes de ervilha, originärias de plantas que receberam nitrogénio,plan tas que receberam nitrogênio e fósforo e plantas que não receberam adubos, verificou, em experimento de campo, que apös 2 semanas de 
semeadura as plântulas emergiram respectivamente $84 \%$, $82 \%$ e $82 \%$.0is se ainda que a emergência final foi em torno de $95 \%$ e $100 \%$ para todos os tratamentos, donde se conclui que, na cultura da erviliha, o nitrogênio não influi na velocidade e porcentagem de emergência. Ainda AUSTIN (1965), produzindo sementes de ervilha em estufa de vidro e utilizando solução nutritiva com diferentes do ses de $\mathrm{N}$ e de $\mathrm{P}$, concluiu que sementes produzidas com ausência de nutrientes (testemunha) germinaram mais rapidamente, seguida pelas sementes oriundas dos tratamentos $\mathrm{N}$ e NP.

AUSTIN e LONGDEN (1965), analisando a influência dos nutrientes sobre o desenvolvimento das plantas e desempenho das sementes produzidas, verificaram que a nutrição das plantas de agrião não afeta a constituição das sementes no que diz respeito ao nitrogênio e potássio, enquanto que a concentração de fósforo á afetada. Disseram ainda que as sementes dos diversos tratamentos possuiam ta manho semelhante e apresentavam o mesmo percentual de germinação.Os mesmos autores destacaram que, em ervilha, a deficiência de nitrogê nio das plantas mães não provoca efeito sobre o desempenho das sementes.

De acordo com AUSTIN e LONGDEN (1966), que estudaram o efeito da adubação mineral (NPK) e orgânica sobre a produção e a qualidade de sementes de cenoura, o tratamento com presença de nitrogênio beneficiou a produção, isto é, quando havia alta densidade de plantas. Concluiram também que a aplicação de nitrogênio não afe 
tou a germinação, assim como a emergência das plântulas no campo. Analisando a composição das sementes, verificaram ainda que aquelas originárias de plantas com altos níveis nitragênio, na análise química relativa ao teor de fósforo e potássio, revelaram baixos teó res.

Hawthorn e Pollard, citados por SOFFER e SMITH(1974c), encontraram uma relação inversa entre a aplicação de nitrogênio no solo e a produção e germinabilidade das sementes de ervilha, isto é, quanto mais rico o solo em $\mathrm{N}$, menor a produção e a porcentagem de germinação das sementes.

GILL et alii (1975), estudando a influência de três diferentes níveis de $N$ e $P$, sobre a produção de sementes de couveflor, em 2 anos consecutivos, concluiram que a produção de sementes fol grandemente influenciada quando se aplicava os maiores niveis de $N$ e $P$. Quando se aumentava apenas o N, apresentou resultados significativos somente no primeiro ano.

CAMPOS et alii (1975) estudaram o efeito de niveis e modo de aplicação de fertilizantes na germinação de sementes de quiabo e concluiram que, o modo de aplicação, associado a níveis elevados de fertilizantes, prejudica a germinação das sementes. Segundo o que se verifica na literatura existente, com referència à alface (Lactuca sativa L.), constata-se que, além dos nutrientes, fatores como instalação e condução da cultura, exercem influência marcante sobre a produção e qualidade das sementes. 
Segundo KNOTT (1957), a semente de alface germina com a temperatura do solo variando de $4,5^{\circ} \mathrm{C}$ a $26^{\circ} \mathrm{C}$, e a temperatura média mensal do ar, mais indicada para o bom desenvolvimento e produção dessa cultura, estä entre $15,5^{\circ} \mathrm{C}$ e $18,3^{\circ} \mathrm{C}$.

KOSAR e THOMPSON (1957), trabalhando com armazenamen to de sementes de alface a $10^{\circ} \mathrm{C}$ e variando a umidade relativa, durante 4 anos, concluiram que a melhor resposta para as sementes durante este período foi com uma umidade relativa compreendida entre $46 \%$ e $58 \%$

Tambëm BACCHI (1960), estudando durante 4 anos o efeito da umidade relativa e temperatura sobre a longevidade das sementes armazenadas de alface (Lactuca sativa L.), mostrou que a lon gevidade das sementes decresce com o aumento da umidade relativa e temperatura.

Para o desenvolvimento da cultura de alface ( Lactuca sativa L.), foi constatado por GRANCO e COUTO (1962) que o nitrogènio é o nutriente que promove maior aumento na produtividade. Em se gundo lugar aparece o fósforo. A interação nitrogênio e fósforo ë significativa e a utilizaçäo conjunta desses dois elementos provoca um aumento na produção de massa verde.

Muitos fatores podem influir na qualidade das sementes de alface.

THOMPSON (1937) observou o efeito da adubação N P K, em ensaios de vasos, sobre a qualidade de sementes de alface. Em 2 
anos de trabalho, verificou que as sementes provenientes de plantas adubadas apresentaram porcentagem de germinação significativamente superior àquelas que não receberam adubo.

0 autor observou também, que as sementes colhidas nas primeiras colheitas apresentaram menor poder germinativo do que aquelas de colheitas posteriores, isto é, em plantas fisiologicamente mais velhas.

Em trabalho citado por HARRINGTON (1960), Hawthorn e Pollard (1956) observaram que a viabilidade de sementes de alface, produzidas em parcelas férteis, não fol influenciada pelos niveis de nitrogênio e fósforo.

HARRINGTON (1960), trabalhando com sementes de alface, cenoura e pimenta, em vasos com solução nutritiva, estudou a in fluência de $N, P, K$ e Ca sobre a germinação e produção de sementes. Concluiu que os resultados de germinação, para as sementes oriundas de tratamentos com baixas doses de $N$, não diferiram daquelas originärias de solução completa e que a produção de sementes foi reduzida com baixos níveis de $N$.

SCAIFE e JONES (1970) encontraram uma alta correlação entre o peso das sementes de alface e o peso da massa verde das plan tas colhidas. Salientaram ainda, que o experimento foi instalado em condições uniforormes e ausência completa de competição entre plantas. Para avaliar je o vigor pode ser um indicador de com portamento da cultura de alface em condições de campo. SMITH et alii 
(1973) realizaram uma série de testes e concluiram que existe uma relação entre o vigor e peso das sementes e que, as sementes menos ví gorosas, são mais lentas em seu crescimento quando colocadas no campo e que produzem um número significativamente inferior de plântulas. Disseram ainda que o vigor das sementes pode ser usado para avaliar o potencial de desempenho no campo.

SOFFER e SMITH (1974b), estudando a qualidade de sementes de alface que diferlam quanto ao tamanho e peso, encontraram que as plantas originárias de sementes grandes e pesadas tiveram inicialmente um desenvolvimento maior que as provenientes de sementes pequenas e leves. Com a continuação do desenvolvimento da cultü ra, no estágio da floração, as plantas provenientes de sementes pequenas e leves se equipararam em crescimento às plantas provenientes de sementes grandes e pesadas. Concluiram ainda que não houve di ferença significativa quanto à produção.

SHARPLES e KUEHL (1974) trabalharam com quatro varie dades de alface e verificaram que o vigor das plântulas fol altamen te correlacionado com o peso \& tamanho das sementes, sendo que o pe so das sementes mostrou-se mais importante do ṇue o tamanho.

SOFFER e SMITH (1974a), estudando a relação entre o florescimento, produção e qualidade de sementes de alface, concluiram que a produção e qualidade de sementes não foram afetadas por colheita precoce, carência de chuvas ou de nutrientes, durante a úl tima metade do período de florescimento. 
SOFFER e SMITH (1974ع), estudando os efeitos nutriclonais sobre a produção e qualidade das sementes de alface, encontraram uma correlação positiva entre níveis de $N$, produção de semen tes, peso de sementes e vigor das plântulas. 0 aumento dos níveis de nutrientes afetou o peso das sementes, composição e o desempenho das plântulas.

Scaife e Jones; Sharples: Smith: Welch e Little, todos citados por SOFFER e SMITH (1974C), encontraram uma correlação positiva entre o peso da semente de alface, tamanho e o vigor das plântulas.

No que diz respeito à influência dos macronutrientes na produção e qualidade das sementes, apesar da literatura escassa e contraditória, a maloria das pesquisas realizadas comprovaram que estes nutrientes, muitas vezes, influem a ponto de limitar a produção e produtividade das hortaliças. Para o caso da alface, foi cons tatado que o $\mathrm{N}$ é o elemento de maior importância, tanto para produção da massa verde, quanto para produção de sementes. 
15.

4. MATERIAL E METODO

\section{1 - Instalação do Ensaio}

O experimento de campo fol executado na ärea experimental do Setor de Horticultura do Departamento de Agricultura e Horticultura, da Escola Superior de Agricultura "Luiz de Queiroz". em Piracicaba, SP.

O solo da área experimental é Latossol série "Luiz de

Quelroz" (RANZANI et alii, 1966). A análise de solo, feita no labo ratório da Ultrafértil S.A., em São Paulo, forneceu os resultados apresentados no Quadro 1.

A determinação do nitrogênio foi feita no Centro de Estudos de Solo e Geologia da ESALQ e apresentou um teor de 0,178\%: 
Quadro 1 - Características químicas do solo da área experimental.

\begin{tabular}{|c|c|c|c|c|c|}
\hline \multirow{2}{*}{$\mathrm{PH}$} & \multirow{2}{*}{$\begin{array}{c}\% \\
\text { Carbono }\end{array}$} & \multirow{2}{*}{$\mathrm{P}_{4}^{--}$} & \multicolumn{3}{|c|}{$\begin{array}{l}\text { Equiv. Miligrama } p / 100 \text { Milili } \\
\text { tros de Terra Fina Seca ao AT }\end{array}$} \\
\hline & & & $\mathrm{K}^{+}$ & $\mathrm{Ca}^{+t} \mathrm{Mg}^{+t}$ & $\mathrm{Al}^{+++}$ \\
\hline 5,6 & 2,80 & 0,60 & 0,53 & 8,80 & 0,00 \\
\hline
\end{tabular}

O solo, após receber o devido preparo, foi nivelado com o objetivo de facilitar as irrigaçōes por sulco. Foi feita uma adubação básica de $20 \mathrm{~g} / \mathrm{m}^{2}$ de $P_{2} O_{5}$ e $6 \mathrm{~g} / \mathrm{m}^{2}$ de $K_{2} O$, recomendada por FILGUEIRA (1972), isto para uma maior uniformidade, usando-se respec tivamente, 0 superfosfato simples $\left(20 \%\right.$ de $\left.P_{2} O_{5}\right)$ e o cloreto de potás sio $\left(60 \%\right.$ de $\left.K_{2} O\right)$.

Utilizou-se sementes de alface (Lactuca sativa L.), da cultivar Gorga, por ter bom comportamento em quase todos os meses do ano (SIMAO, 1960). Apresenta-se com folhas crespas e tenras, aceita pelos consumidores. Floresce com aproximadamente 100 dias após a semeadura e encerra o ciclo (vegetativo e reprodutivo) aos 150-180 dias.

A semeadura fol efetuada em canteiros no dia 16 de jü nho de 1976. O canteiro foi coberto com folhas de palmeira e isolado com tela de nylon. 
As plantas foram irrigadas diariamente na sementeira com regador.

As mudas foram transplantadas para o campo no dia 21 de julho de 1976, tendo sido selecionadas as mais vigorosas.

O replantio das mudas que falharam foi felto 5 dias após o transplante.

Os tratamentos fitossanitários foram feitos sistematicamente à base de Maneb e Zineb para proteger o experimento das doenças e com Mevinphos e Endrin, para controle das pragas. As dosa gens foram as indicadas pelos fabricantes. As capinas foram feitas entre fileiras com cultivador e entre plantas com enxada.

O delineamento usado no ensaio de adubação obedeceu ao de blocos casualizados, com 4 tratamentos e 4 repetições. Os tra tamentos corresponderam aos diversos níveis de nitrogēnio, conforme segue no Quadro 2.

Quadro 2 - Quantidades de sulfato de amônio usadas nos tratamentos do experimento.

$\begin{array}{rlc}\text { TRATAMENTOS } & \text { Sulfato de amōnlo }\left(\mathrm{g} / \mathrm{m}^{2}\right) \\ A=\text { Testemuntia } & 0 \\ B=\text { Nível I } & 10 \\ C=\text { Nível II } & 20 \\ D=\text { NÍvel III } & 40\end{array}$


Foram aplicadas as mesmas quantidades no plantio e em cobertura a cada 15 dias (FILGUEIRA, 1972), até que as plantas at1n gissem 120 dias após serem transplantadas.

0 espaçamento 1niclal fol de $1,00 \mathrm{~m} \times 0,40 \mathrm{~m}$ até aos 90 dlas depols da semeadura. Nesta data, efetuou-se o desbaste, f1cando as plantas distando de $1,00 \mathrm{~m}$ entre f1le1ras e $0,80 \mathrm{~m}$ entre plantas, permanecendo a partir dai, apenas 20 plantas úte1s por par cela. A área útil da parcela fol de $14,40 \mathrm{~m}^{2}$, considerando-se somen te as duas IInhas centrals.

\section{2 - Testes Preliminares}

As sementes foram colhidas manualmente e homogenelza das cada repetição, em divisor de amostras Centrifugo Dean Gamet, em novembro de 1976. Feito 1sto, foram pesadas as sementes de cada um dos tratamentos. Em seguida, efetuou-se os testes de pureza físi ca, de uma amostra de cada tratamento e germinação, assim como a de terminação do teor de umidade, com o objetivo de caracterizar o materlal que fol analisado no transcorrer do trabalho. Os testes de pu reza física e germinação, além da determinação do teor de umijade (mëtodo da estufa a $105^{\circ} \mathrm{C}$ ), foram efetuados de acordo com as Regras para Análise de Sementes (BRASIL, M.A., 1967). 


\section{3 - Testes de Laboratörio}

As análises foram realizadas no Laboratório de Semen tes do Departamento de Agricultura e Horticultura, da Escola Superior de Agricultura "Luiz de Queiroz", Universidade de São Paulo,em Piracicaba, SP.

As sementes permaneceram armazenadas em câmara seca, com $35 \%$ de umidade relativa do ar e temperatura média de $23^{\circ} \mathrm{C}$, no próprio Laboratório de Sementes, no período compreendido entre dezembro de 1976 a junho de 1977. Durante esse período, foram efetuados testes de germinação e de vigor, peso de mil sementes e determi nação do teor de umidade das sementes, em quatro épocas distintas,a saber: dezembro de 1976, fevereiro, abril e junho de 1977. Essas épocas foram designadas, no presente trabalho, por $E_{1}, E_{2}, E_{3}$ e $E_{4}$, respectivamente.

\subsection{1 - Germinação}

Os testes de germinação foram realizados com 4 repetiçōes de 50 sementes, para cada tratamento,e colocadas em germinador marca BURROWS, à temperatura constante de $20^{\circ} \mathrm{C}$.

As sementes foram colocadas sobre papel chupão especial, em calxa de plästico transparente ("gerbox") e a avaliação das plântulas foi realizada aos 7 dias após a instalação dos testes, se gundo critérios das Regras para Análise de Sementes (BRASIL, M.A., 
1967).

\subsection{2 - Primeira contagem de germinação}

Este método fol realizado para determinar quais os tratamentos mais vigorosos. Fol realizado em conjunto com os testes de germinação. Constou do reg1stro da porcentagem de plântulas normais (CAMARGO e VECCHI, 1971) e executado no quarto dia após a instalação de cada teste.

\subsection{3 - Emergência}

Os testes de velocidade de emergêncla e porcentagem de emergència foram conduzidos em canteiros, no setor de Horticultu ra do Departamento de Agricultura e Horticultura da Escola Superior de Agricultura "Luiz de Que1roz", constando cada tratamento de 4 re pet1ções de 50 sementes. Cada uma dessas repetições constou de uma linha de 1,00 m de comprimento, na qual fol efetuada a semeadura, distando $0,10 \mathrm{~m}$ de cada. As sementes foram distribuidas a uma profundidade de $0,5 \mathrm{~cm}$, tomando-se o culdado de se fazer com que o espaçamento entre as sementes fosse uniforme e constante.

Durante o desenvolvimento dos testes, o solo fol man tido com umidade suficlente para proporcionar boas condiçōes para a emergència das plântulas.

A partir da emergência da primeira plântula, foram 
efetuadas contagens diárias do número de plântulas emergidas, até que esse número se mantivesse constante para cada uma das parcelas (THRONEBERRY \& SMITH, 1955; MAGUIRE, 1962). Foram consideradas emer gidas as plêntulas cujo comprimento da plúmula era de aproximadamen te $0,5 \mathrm{~cm}$.

Após a estabilidação da emergência, computou-se a por centagem de emergência. A velocidade de emergência fol calculada se gundo MAGUIRE (1962), por melo da seguinte fórmula:

$$
V E=\frac{N_{1}}{D_{1}}+\frac{N_{2}}{D_{2}}+\ldots+\frac{N_{n}}{D_{n}},
$$

onde: $V E=$ velocidade de emergência;

$$
\begin{aligned}
N_{1}, N_{2}, N_{n}= & \text { número de plântulas emergidas na primeira, se- } \\
& \text { gunda e última contagem, respectivamente, } \\
D_{1}, D_{2}, D_{n}= & \text { número de dias decorridos da semeadura à prime1 } \\
& \text { ra, segunda e última contagem, respectivamente. }
\end{aligned}
$$

\subsection{4 - Peso de 1000 sementes}

Fol determinado o peso de 1000 sementes de cada tratamento, nas quatro épocas, segundo as Regras para Anál1se de Semen tes (BRASIL, M. $A_{0}$, 1967).

\subsection{5 - Determinação de umidade}

Durante o desenvolvimento do trabalho, isto é, por ocasião de cada época do período experimental, a umidade das semen- 
tes foi determinada, em estufa a $105^{\circ} \mathrm{C}$, durante 24 horas, conforme as Regras para Anālise de Sementes (BRASIL, M.A. . 1967).

\section{4 - Anälise Química das Sementes}

A anālise química das sementes foi realizada no Labo ratörio de Nutrição de Plantas, do Centro de Energia Nuclear na Agri cultura - CENA (ESALQ/USP), visando à obtenção dos teores de nitro gënio, fósforo e potássio.

A metodologia usada para determinação desses elementos foi a convencionalmente adotada na ärea de Nutrição de Plantas do Departamento de Química da ESALQ, e descritas em SARRUGE e HAAG (1974).

\section{5 - Estudos de Campo}

Apōs a obtenção dos resultados de laboratórío, foram semeadas, em 15 de abril de 1977, sementes oriundas dos quatro tratamentos, com o objetivo de determinar o peso da matéría seca das plantas aos 20 dias após semeadura e o peso da matëria fresca das mesmas, no ponto de colheita.

Para o plantio comercial, fol feita uma adubação básica e uniforme a todos os tratamentos, de $20 \mathrm{~g} / \mathrm{m}^{2}$ de $P_{2} O_{5}=1 \mathrm{~g} / \mathrm{m}^{2}$ de $N_{\text {, a cada }} 15$ dias, perfazendo um total de $3 \mathrm{~g} / \mathrm{m}^{2}$ e $6 \mathrm{~g} / \mathrm{m}^{2}$ de $\mathrm{K}_{2} \mathrm{O}$ (FILGUEIRA, 1972), usando-se respectivamente o superfosfato simples 
$\left(20 \%\right.$ de $\left.P_{2} \mathrm{O}_{5}\right)$, o sulfato de amônio $(20 \%$ de $N)$ e o cloreto de potássio $\left(60 \%\right.$ de $\left.K_{2} 0\right)$.

\subsection{1 - Determinação da matēria seca das plantas}

Após 20 dias de semeadas, foram retiradas 60 mudas por tratamento, isto é, 15 mudas por repetição, para se determinar - peso da matéría seca. Este material permaneceu 24 horas sobre papel toalha de marca "Xuga", com a finalidade de perder o excesso de umidade. Em seguida, foram conduzidas a uma estufa, regulada a uma temperatura de $50^{\circ} \mathrm{C}$, permanecendo até que o material atingisse peso constante. O peso da matéria seca das plantas foi determinado em ba lança analftica Mettler, modelo $\mathrm{k}-7$, com precisão de $0,01 \mathrm{~g}$.

\subsection{2 - Determinação do peso da matēria fresca das plantas}

A colheita das plantas, ao atingir o ponto de colhei ta, fol efetuada em quatro épocas, ou seja: 30 de junho, 4 de julho, a de julho e 12 de julho de 1977 , respectivamente, $E_{1}, E_{2}, E_{3}$ e $E_{4}$. As plantas colhidas foram imediatamente lavadas, pesadas e anotadas.

\section{6 - Método Estatístico}

Os dados obtidos nos testes de germinação, primeira contagem de germinação, porcentagem de emergêncla e anālise química das sementes, foram transformados em arc sen $\sqrt{\%}$, conforme SNEOECOR (1948) e analisados estatisticamente. 
A análise dos dados obtidos de todos os valores determinados, obedeceu aos esquemas que se encontram nos Quadros 3 e 4. de acordo com PIMENTEL GOMES (1970).

Quadro 3 - Esquema utilizado para anälise de variância empregado nas determinações de $N, P, K$ e determinaçöes referentes ao ensaio de campo.

\begin{tabular}{lc}
\hline Causas de Variação & G.L. \\
\hline Blocos & 3 \\
Tratamentos & 3 \\
Residuo & 9 \\
\hline Total & 15 \\
\hline
\end{tabular}

Quadro 4 - Esquema utilizado para anälise de variancia, empregado nas quatro épocas da velocidade e porcentagem de emergèn cla, peso de 1000 sementes, porcentagem de germinação e primeira contagem de germinação.

\begin{tabular}{lc}
\hline Causas de Variação & G.L. \\
\hline Epocas & 3 \\
Tratamentos & 3 \\
Residuo & 9 \\
\hline To t a 1 & 15 \\
\hline
\end{tabular}


0 teste adotado fol o de Tukey, para a comparação en tre as médlas, ao nível de $5 \%$ de probabilidade.

As análises foram executadas no Departamento de Mate mática e Estatistica da Escola Superior de Agricultura "Luiz de Que1 roz", da Universidade de Säo Paulo. 
26.

5. RESULTADOS

\section{1 - Produção de Sementes}

A anälise da variância dos dados referentes à produção de sementes, revelou valores de $F$ näo significativos, ao nível de $5 \%$ de probabilidade, para os efeitos de tratamentos.

o Ruadro 5 mostra os resultados obtidos dos quatro tratamentos, nas quatro repetições, e o coeficiente de variação.

Quadro 5 - Produção de sementes. Resultados obtidos nas quatro repe tições (em gramas/parcela).

\begin{tabular}{cccccc}
\hline & \multicolumn{6}{c}{ REPETIÇOES } & X \\
\cline { 2 - 5 } TRATAMENTOS & I & II & III & IV & \\
\hline A & 403,9 & 497,5 & 397,0 & 450,7 & 437,27 \\
B & 354,0 & 384,0 & 479,3 & 346,9 & 391,05 \\
C & 488,3 & 311,1 & 291,3 & 563,4 & 413,52 \\
$D$ & 278,0 & 358,4 & 485,1 & 358,9 & 370,10 \\
\hline
\end{tabular}

$C . V_{*}=24,39 \%$ 


\section{2 - Testes Preliminares}

Em seguida tem-se, através do Quadro 6, os resultados obtidos nas determinações do teor de umidade, porcentagem de pu reza e de germinação.

Quadro 6 - Teor de umidade, porcentagem de pureza e germinação.

\begin{tabular}{cccc}
\hline TRATAMENTOS & $\begin{array}{c}\text { Teor de } \\
\text { umidade } \\
(\%)\end{array}$ & $\begin{array}{c}\text { Pureza } \\
(\%)\end{array}$ & $\begin{array}{c}\text { Germinação } \\
(\%)\end{array}$ \\
\hline A & 9,1 & 97,0 & 94 \\
B & 9,2 & 97,4 & 96 \\
C & 9,4 & 98,6 & 98 \\
D & 9,3 & 96,1 & 96 \\
\hline
\end{tabular}

5.3 - Testes de Laboratörio

\subsection{1 - Germinação}

A anălise da variancia dos dados obtidos, referentes aos estudos de germinação, mostrou valores do $F$ não significativos. ao nivel de $5 \%$ de probabilidade.

Os valores médios obtidos das quatro repetiçães, para as quatro épocas testadas, e o coeficiente de variação, acham-se no Quadro 7. 
Quadro 7 - Germinaçäo. Resultados obtidos nas quatro ëpocas $[x=$ arc $\operatorname{sen} \sqrt{\%}$ ).

\begin{tabular}{ccccc}
\hline & \multicolumn{4}{c}{ EPOCAS } \\
\cline { 2 - 5 } TRATAMENTOS & $1 !$ & $2 !$ & $3 !$ & $4 !$ \\
\hline A & 77,56 & 81,54 & 79,31 & 82,20 \\
B & 78,65 & 82,20 & 80,03 & 77,74 \\
C & 82,39 & 83,57 & 84,42 & 76,77 \\
D & 79,31 & 75,91 & 83,90 & 80,32 \\
\hline
\end{tabular}

\subsection{2 - Primeira contagem de germinação}

A anälise de varíância dos dados obtidos, referentes à primeira contagem de germinação, revelou valores de F não signifi cativos, ao nível de $5 \%$ de probabilidade.

No Quadro 8 encontram-se os valores médios obtidos das quatro repetições, para as quatro épocas testadas, e o coeficiente de varíação.

Quadro 8 - Vigor: Primeira contagem de germinação. Resultados obt1dos nas quatro épocas $(x=\operatorname{arc} \operatorname{sen} \sqrt{\%})$.

\begin{tabular}{ccccc}
\hline \multirow{2}{*}{ TRATAMENTOS } & \multicolumn{3}{c}{ EPOCAS } & \\
\cline { 2 - 5 } & 1. & 29 & $3 !$ & 4. \\
\hline A & 71,76 & 76,58 & 78,46 & 73,46 \\
B & 75,86 & 77,99 & 77,73 & 72,85 \\
C & 79,81 & 81,54 & 83,57 & 74,74 \\
$D$ & 76,74 & 73,36 & 80,16 & 76,92 \\
\hline
\end{tabular}

$C \cdot V \cdot=3,56 \%$ 


\subsection{3 - Emergência}

A aplicação da análise da variância mostrou, para os dados referentes à velocidade e porcentagem de emergência, va lores de F significativos para épocas, a nível de 1\% de probabilida de. Quanto ao efeito dos tratamentos, verificou-se que não foram sig nificativos, ao nível de $5 \%$ de probabilidade.

0 teste de Tukey constatou, para velocidade e porcen tagem de emergência, que as épocas $E_{2}, E_{3}$ e $E_{4}$ são significativamen te superiores à época $E_{1}$, ao nível de $1 \%$ de probabilidade, mas não diferem entre si.

No Ruadro 9 encontram-se os resultados obtidos de quatro repetições, para as quatro épocas, a diferença mínima signi-

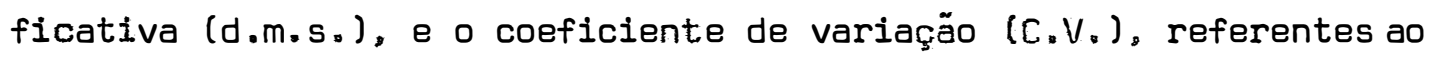
teste de velocidade de emergência.

Quadro 9 - Vigor: Velocidade de emergência. Resultados obtidos nas quatro épocas ( $x$ = Índice de velocidade de emergência).

\begin{tabular}{|c|c|c|c|c|}
\hline \multirow{2}{*}{ TRATAMENTOS } & \multicolumn{4}{|c|}{ EPOCAS } \\
\hline & 1 ? & 2 . & 3 ? & 4 ? \\
\hline A & 9,46 a & 14,76 & $14,67 \mathrm{a}$ & 14,45 \\
\hline$B$ & 7,69 b & 14,06 & $13,83 a b$ & 14,81 \\
\hline C & $7,73 \mathrm{~b}$ & 15,10 & $13,29 \mathrm{~b}$ & 14.31 \\
\hline D & $7,34 \mathrm{~b}$ & 15,40 & 13,65 ab & 14,73 \\
\hline d.m.s. $5 \%$ (Tuk & \multicolumn{4}{|c|}{1,25} \\
\hline
\end{tabular}


Os resultados obtidos das ciuatro épocas, referentes à porcentagem de emergência, a diferença mínima significativa (d.m. s.), e o coeficiente de variação (C.V.), acham-se no Quadro 10.

Quadro 10 - Vigor: Porcentagem de emergência. Resultados obtidos nas quatro épocas $(x=\operatorname{arc} \operatorname{sen} \sqrt{\%}\}$.

\begin{tabular}{|c|c|c|c|c|}
\hline \multirow{2}{*}{ TRATAMENTOS } & \multicolumn{4}{|c|}{ EPOCAS } \\
\hline & 1. & 2 . & $3 ?$ & 4 ? \\
\hline A & 53,43 a & 72,05 & 73,05 & 70.18 \\
\hline$B$ & $44,71 b$ & 70,18 & 68,87 & 73,57 \\
\hline C & $44,71 \mathrm{~b}$ & 77,08 & 67,62 & 71,56 \\
\hline D & $45,86 b$ & 77.08 & 69,73 & 74,66 \\
\hline d.m.s. $\quad 5 \%(T u$ & & & & \\
\hline
\end{tabular}

C.V. $=4,98 \%$

\subsection{4 - Peso de 1000 sementes}

A anảlise estatistica dos dados relativos ao peso de 1000 sementes mostrou, para tratamentos; velores de F significativos, ao nivel de $1 \%$ de probabilidade. Ruanto às énocas, verificou- se que não foram significativas, ao nível de $5 \%$ de probabilidade. O teste de Tukey constatou que o tratamento $C$ (nível II) è slgnificativanente supertor ao tratamento $A$ (testemunha), ao nível de $1 \%$ de probabilidade, e dos tratamentos $\theta$ (nível I) e 0 (ní vel III), ao nive? de $5 \%$ de probabilidade. Os tratamentos $\theta$ (nível 
I) e $D$ (nf́vel III) são significativamente superiores ao tratamento A (testemunha), ao nivel de $1 \%$ de probabilidade.

No Quadro 11 encontram-se os resultados obtidos para cada tratamento, nas quatro épocas, a diferença mínima significativa (d.m.s.) e o coeficiente de varlaçäo (c.v.).

Quadro 11 - Peso de 1000 sementes. Resultados obtidos nas quatro épocas (em gramas/tratamento).

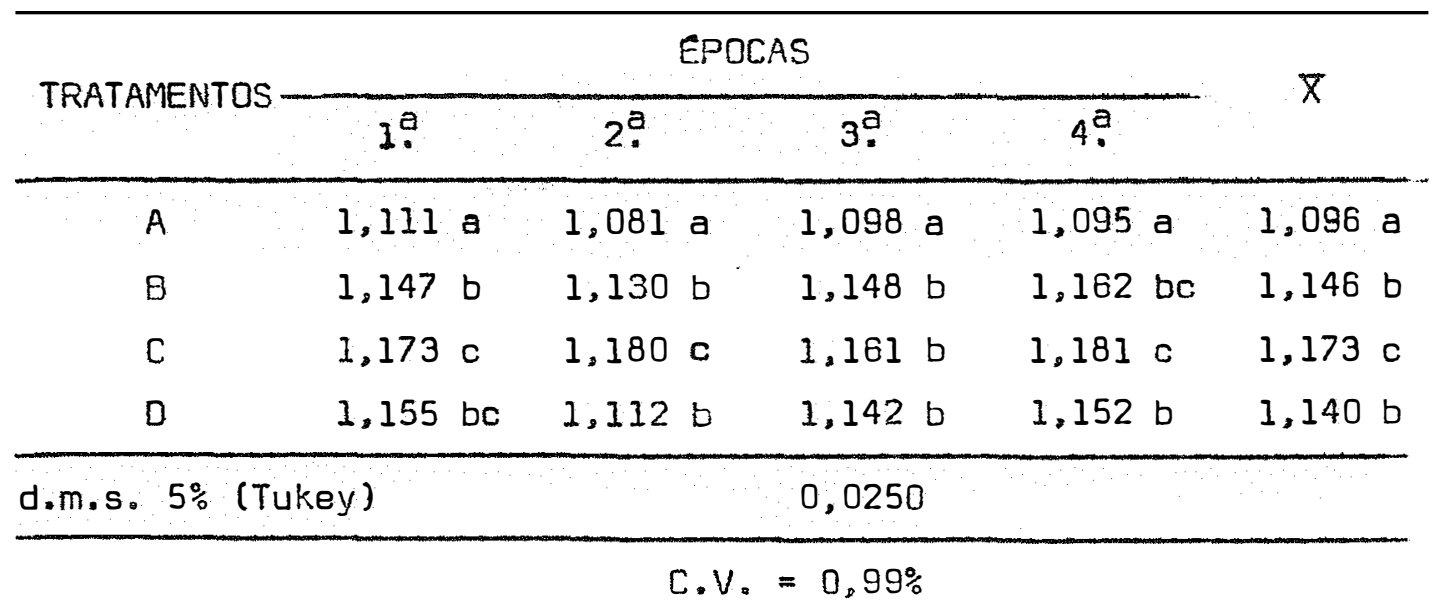

\subsection{5 - Determinação de umidade}

No quadro 12 apresentam-se os resultados obtidos para cada tratamento, nas quatro épocas, referentes às determinações do teor de umidade. 
Quadro 12 - Umidade das sementes armazenadas em câmara seca nas qua tro épocas. Mëdias de duas repetiçōes $(\%)$.

\begin{tabular}{ccccc}
\hline \multirow{2}{*}{ TRATAMENTOS } & \multicolumn{4}{c}{ EPOCAS } \\
\cline { 2 - 5 } & $1^{\mathrm{a}}$ & 2. & 3. & 4. \\
\hline A & 5,8 & 6,5 & 6,5 & 7,5 \\
B & 5,6 & 6,2 & 6,7 & 7,5 \\
C & 6,0 & 6,3 & 6,3 & 7,4 \\
D & 5,9 & 6,6 & 6,9 & 7,1 \\
\hline
\end{tabular}

\section{4 - Anälise Química das Sementes}

\subsection{1 - Determinação de nitrogênio}

A análíse da varianncla dos dados obtidos, referentes à determinaçäo de nitrogênio, revelou valores de $F$ não significativos, ao nivel de $5 \%$ de probabilidade, para os efeitos de tratamentos.

No quadro 13 encontram-se os resultados obtidos nas quatro repetições dos quatro tratamentos, e no nuadro 14, os mesmos resultados, transformados em arc sen $\sqrt{\%}$, e o coeficiente de variaçäo $\left(\dot{C} \cdot V_{0}\right)$. 
Quadro 13 - Determinação de nitrogênio. Resultados obtidos nas quatro repetições $\{\%\}$.

\begin{tabular}{|c|c|c|c|c|c|}
\hline \multirow{2}{*}{ TRATAMENTOS } & \multicolumn{4}{|c|}{ REPETICOES } & \multirow{2}{*}{$\bar{x}$} \\
\hline & $I$ & II & III & IV & \\
\hline A & 6,78 & 7,15 & 6,99 & 7,08 & 7,00 \\
\hline$B$ & 7,25 & 6,84 & 6,92 & 7,68 & 7,17 \\
\hline C & 8.77 & 7,05 & 7,38 & 7,06 & 7.06 \\
\hline D & 7,93 & 6.75 & 7,56 & 7,82 & 7,51 \\
\hline
\end{tabular}

Quadro 14 - Determinação de nitrogênio. Resultados obtidos nas nุuatro repetições. $(x=\operatorname{arc} \operatorname{sen} \sqrt{\%})$.

\begin{tabular}{|c|c|c|c|c|c|}
\hline \multirow{2}{*}{ TRATAMENTOS } & \multicolumn{4}{|c|}{ REPETIÇŐES } & \multirow{2}{*}{$\bar{x}$} \\
\hline & I & II & III & IV & \\
\hline A & 15,12 & 15,45 & 15,34 & 15,45 & 15,34 \\
\hline$B$ & 15,56 & 15.12 & 15,23 & 16,11 & 15,51 \\
\hline c & 15,12 & 15,34 & 15,79 & 15,45 & 15,43 \\
\hline D & 16,32 & 15,12 & 16,00 & 16,22 & 15,92 \\
\hline
\end{tabular}

\section{4 .2 - Determinação de fósforo}

A anălise de variāncia dos dados obtidos, referentes à determinação de fósforo, revelou, para tratamentos, valores de $F$ significativos, ao nível de $1 \%$ de probabilidade.

0 teste de Tukey constatou nue o tratamento A (teste 
munha) é significativamente superior aos tratamentos C (nível II) e D (nível III), ao nível de $1 \%$ de probabilidade, e do tratamento B (nIvel I), ao nível de 5\% de probabilidade. Os tratamentos a inível I), C (nível II) e D (nível III), não diferiram entre si.

No quadro 15 encontram-se os resultados obtidos nas quatro repetiçōes, dos quatro tratamentos, e no Quadro 16, os mesmos resultados transformados em arc sen $\%$, a diferença mínima significativa (d.m.s.) e o coeficiente de variação (C.V.).

Quadro 15 - Determinação de fósforo. Resultados obtidos nas quatro repetições $(\%)$.

\begin{tabular}{|c|c|c|c|c|c|}
\hline \multirow{2}{*}{ TRATAMENTOS } & \multicolumn{4}{|c|}{ REPET IÇÕES } & \multirow{2}{*}{$\bar{x}$} \\
\hline & $I$ & II & III & IV & \\
\hline A & 1,36 & 1,35 & 1,32 & 1,32 & 1,33 \\
\hline$B$ & 1,29 & 1,28 & 1,23 & 1,26 & 1.26 \\
\hline C & 1.29 & 1,23 & 1,28 & 1,20 & 1,25 \\
\hline$D$ & 1,28 & 1,23 & 1.24 & 1,26 & 1,25 \\
\hline
\end{tabular}

Quadro 16 - Determinação de fósforo. Resultados obtidos nas quatro repetições $(x=\operatorname{arc} \operatorname{sen} \sqrt{\%})$.

\begin{tabular}{|c|c|c|c|c|c|}
\hline \multirow{2}{*}{ TRATAMENTOS } & \multicolumn{4}{|c|}{ FEPET IÇÕES } & \multirow{2}{*}{$\bar{x}$} \\
\hline & $I$ & II & III & IV & \\
\hline A & $6,70 \mathrm{a}$ & $6,67 \mathrm{a}$ & 6,60 a & $6,60 \mathrm{a}$ & 6,64 a \\
\hline$B$ & $6,52 b$ & $6,49 \mathrm{~b}$ & $6,37 \mathrm{~b}$ & $6,45 \mathrm{~b}$ & $6,46 \mathrm{~b}$ \\
\hline$D$ & $6.52 \mathrm{~b}$ & $6,37 b$ & $6,50 \mathrm{ab}$ & $6.29 \mathrm{c}$ & $6.42 \mathrm{~b}$ \\
\hline$D$ & $6,49 b$ & $6.37 \mathrm{~b}$ & $6,39 \mathrm{~b}$ & $6,45 \mathrm{~b}$ & $6,43 \mathrm{~b}$ \\
\hline \multicolumn{2}{|c|}{ d.m.s. $5 \%$ (Tukey) } & & 0,14 & & \\
\hline
\end{tabular}




\subsection{3 - Determinação de potässio}

A anälise de variância dos dados obtidos, referentes à determinação de potássio, revelou, para tratamentos, valores de $F$ significativos ao nivel de $1 \%$ de probabilidade.

O teste de Tukey constatou que o tratamento $A$ (teste munha) é significativamente superior aos tratamentos C (nível II) e D (nível III), ao nível de $1 \%$ de probabilidade, e ao tratamento B (nível I), ao nível de $5 \%$ de probabilidade. Os tratamentos $\mathrm{E}$ (nível I),C (nível II) e D (nível III), não diferiram entre si.

No Quadro 17 encontram-se os resultados obtidos nas quatro repetições, dos quatro tratamentos, e no Quadro 18, os mesmos resultados, transformados em arc sen $\sqrt{\%}$, a diferença mínima sig: nificativa $\left(d . m_{\circ} S_{0}\right)$ e o coeficiente de variação (C.V.).

Quadro 17 - Determinação de potássio. Resultados obtidos nas quatro repetições $(\%)$,

\begin{tabular}{cccccc}
\hline & \multicolumn{2}{c}{ REPETIÇÕES } & \\
TRATAMENTOS & I & II & III & IV & $\bar{X}$ \\
\hline A & 1,30 & 1,20 & 1,20 & 1,10 & 1,20 \\
$B$ & 1,20 & 1,00 & 0,90 & 1,10 & 1,05 \\
$C$ & 1,05 & 0,95 & 1,00 & 0,95 & 0,98 \\
$D$ & 1,00 & 0,95 & 0,90 & 0,90 & 0,93 \\
\hline
\end{tabular}


Quadro 18 - Determinação de potássio. Resultados obtidos nas quatro repetições $(x=\operatorname{arcsen} \sqrt{\%})$.

\begin{tabular}{|c|c|c|c|c|c|}
\hline \multirow{2}{*}{ TRATAMENTOS } & \multicolumn{4}{|c|}{ REPET IC̋OES } & \multirow{2}{*}{$\bar{x}$} \\
\hline & $I$ & II & III & IV & \\
\hline$A$ & 6,55 a & 6,29 a & 6,29 a & 6,02 a & 6.29 a \\
\hline$B$ & $6,29 \mathrm{~b}$ & $5,74 \mathrm{~b}$ & $5,44 b$ & $6,02 a$ & $5,87 b$ \\
\hline$C$ & $5,88 \mathrm{c}$ & $5,59 b$ & $5,74 b$ & $5,59 b$ & $5,70 \mathrm{~b}$ \\
\hline$D$ & $5,74 \mathrm{c}$ & $5,59 b$ & $5,44 b$ & $5,44 b$ & $5,55 \mathrm{~b}$ \\
\hline d.m.s. $5 \%$ & & & 0,36 & & \\
\hline
\end{tabular}

$C_{.} V_{0}=3,04 \%$

\section{5 - Estudos de Campo}

\subsection{1 - Determinação da matëria seca das plantas}

A análise estatística da determinação da matéria seca mostrou, para tratamentos, valores de F significativos, ao nível de $1 \%$ de probabilidade.

O teste de Tukey constatou que o tratamento D [nível III) é significativamente superior aos tratamentos $A$ (testemunha) e B (nível I), ao nível de $1 \%$ de probabilidade, e do tratamento C (ní vel II), ao nível de $5 \%$ de probabilidade. Os tratamentos A (testemu nha), B (nível I) e C (nível II), não diferiram entre si.

Os valores obtidos nas quatro repetições, dos diversos tratamentos, a dî̂erença mínima significativa (d.m.s.) e o coeficiente de variação $(C, V$.$) , encontram-se no quadro 19$. 
Quadro 19 - Determinação de matéria seca. Resultados obtidos nas qua tro repetições, dos diversos tratamentos lem gramas/par cela).

\begin{tabular}{|c|c|c|c|c|c|}
\hline \multirow{2}{*}{ TRATAMENTOS } & \multicolumn{4}{|c|}{ REPETIÇÕES } & \multirow{2}{*}{$\bar{x}$} \\
\hline & I & II & III & IV & \\
\hline A & $0,80 a$ & 0,86 a & 0,66 a & 0,63 a & $0,7375 a$ \\
\hline B & $1.08 \mathrm{~b}$ & 0,91 a & $1,29 \mathrm{~b}$ & $1,17 \mathrm{~b}$ & $1.1125 a$ \\
\hline c & $0.97 \mathrm{~b}$ & 0,97 a & $1,67 \mathrm{~b}$ & $1,06 \mathrm{~b}$ & $1,1675 \mathrm{~b}$ \\
\hline$D$ & $1.86 \mathrm{c}$ & $1.49 \mathrm{~b}$ & $1,80 \mathrm{c}$ & $1,71 \mathrm{c}$ & $1.7150 \mathrm{c}$ \\
\hline \multicolumn{2}{|c|}{ d.m.s. 5\% (Tukey) } & & 0,4332 & & \\
\hline
\end{tabular}

5.5.2 - Determinação do peso da matërla fresca das plantas A anālise da variância dos dados, referentes à produ ção de matéría fresca, revelou valores de F não significativos, ao nivel de $5 \%$ de probabilidade, para os efeitos de tratamentos. No Quadro 20, encontram-se os resultados obtidos nas g̨uatro repetições e o coeficiente de variação. 
38.

Quadro 20 - Produção de matéria fresca. Resultados médios obtidos nas quatro repetiçōes, dos diversos tratamentos (em gra mas/parcelas.

\begin{tabular}{|c|c|c|c|c|c|}
\hline \multirow{2}{*}{ TRATAMENTOS } & \multicolumn{4}{|c|}{ REPETIÇÕES } & \multirow{2}{*}{$\bar{x}$} \\
\hline & $I$ & II & III & IV & \\
\hline$A$ & 230,8 & 241,5 & 217,6 & 298,0 & 246,97 \\
\hline$B$ & 180,1 & 184,9 & 252,7 & 348,8 & 241,62 \\
\hline$C$ & 211,3 & 173,2 & 185,2 & 267,4 & 209,27 \\
\hline 0 & 168,0 & 221,4 & 259,3 & 290,0 & 234,67 \\
\hline
\end{tabular}

C.V. $=13,73 \%$ 
39.

6. DISCUSSAOO

\section{1 - Frodução de Sementes}

Os resultados obticos no presente trabalho contrariam aqueles alcançados por SOFFER e SMITH (1974C) que trabalharam com sementes de alface. HARRINGTON (1960) com sementes de alface, cenou ra e pimenta e HAWTHORN (1952), EGUCHI (1960), Pendleton (citado por HARRINGTON, 1960), AUSTIN \& LONGOEN (1965), DELOUCHE (1971 e 1972) e GIL et alii (1975), que trabalharam com outras hortaliças e que ot tiveram resultados positivos na produção de sementes aumentando-se os níveis de $\mathrm{N}$ no solo. Os resultados obtidos no presente trabalho (Quadro 5) não apresentaram diferenças significativas entre os tratamentos. Possivelmente isso se deva às condições em que o experimento foi conduzido, pois o solo era de alta fertilidade, conforme 
se verifica no Quadro l. Em solos de boas qualidades químicas, uma suplementação com adubo pode não dar resposta muito evidente (REISE NAUER, QUICK e VOSS, 1976). Além disso, algumas hortaliças podem não responder à adubação nitrogenada em termos de produção de semente, ou mesmo responder negativamente, como é o caso da cebola ISTUART e GRIFFIN, 1946) e ervilha (Hawthorn e Pollard, citados por SOrFER e SMITH, 1974c).

\section{2 - Qualidade da Semente}

A qualidade da semente em laboratório foi mensurada através dos testes de germinação, vigor e peso de 1000 sementes.

\subsection{1 - Teste de germinação}

A germinação não foi afetada pelos níveis de $N$, pois os resultados das análises (Quadro 7) não apresentaram diferenças significativas entre os tratamentos. Resultados semelhantes foram ob tidos por HARRINGTON (1960) e Hawthorn e Pollard (citados por HARRINGTON, 1960) também em alface. O nitrogênio parece não afetar diretamente a germinação de sementes de outras hortaliças. Assim, Schu del (citado por HARRINGTON, 1960), em estudos com sementes de cebo1a, EGUCHI (1960), com sementes de repolho, Eguchi (citado por HARRINGTON, 1960), com sementes de couve chinesa, AUSTIN e LONGOEN (1965), com sementes de agrião e ervilha, AUSTIN e LONGDEN (1966). 
com sementes de cenoura e Hawthorn e Pollard lcitados por SOFFER e SMITH, 1974C), com sementes de ervilha, chegaram a resultados semeIhantes.

No entanto, alguns autores como THOMPSON (1937), estu dando sementes de alface, e Pendleton (citado por HARRINGTON, 1960), com sementes de beterraba açụcareira, encontraram influência do nitrogénio na germinação das sementes, não coincidindo com os resulta dos obtidos no presente trabalho.

Ainda com relação ao Quadro 7, observa-se que não hou ve diferença significativa entre a germinação das sementes nas 4 épocas, ou seja, nos 4 períodos de armazenamento. Com isso, pode-se dizer que a cultivar Gorga produz sementes sem dorméncia logo apös a colheita. Em geral, a maioria das cultivares de alface apresentam dormência fisiológica, logo apös a colheita das sementes, havendo necessidade de se armazenar por um período mínimo de 2 a 3 meses,an tes de serem utilizadas.

\section{2 .2 - Testes de vigor}

\subsubsection{1 - Primeira contagem de germinação}

Os resultados da primeira contagem de germinação (Qua dro 8) foram semelhantes aos observados para os testes de germinação. Assim, de um modo geral, constatou-se que não houve influência do nitrogènio nas quatro épocas. 


\subsubsection{2 - Emergência}

Os resultados dos testes de velocidade de emergência e porcentagem de emergéncia (Quadros 9 e 10), foram também semelhan tes aos de germinação e de primeira contagem, quanto aos tratamentos nas quatro épocas; assim, o vigor das sementes mostrou-se indiferente ao aumento do nível de nitrogênio. Resultados idênticos foram obtidos por AUSTIN e LONGDEN (1965) estudando sementes de erviIha e agrião, AUSTIN e LONGDEN (1966) com sementes de cenoura, AUSTIN (1965) com sementes de ervilha e DELOUCHE (1972). Por outro lado, SOFFER e SMITH (1974c) encontraram uma correlação positiva entre níveis de nitrogênio e o vigor das plântulas de alface. Fox e Albrecht (citados por HARRINGTON, 1960) e DELOUCHE (1971), em estudos com outras espécies, concluiram que altas concentrações de nitrogênio têm grande influência sobre o vigor das sementes.

Como se pode verificar, estas observaçōes sugerem a necessidade de novos estudos sobre a influência do $N$ na qualidade de sementes de alface. Os resultados da porcentagem de germinação e dos testes de vigor nas quatro épocas, também não foram afetados pe lo nitrogênio. Provavelmente seja devido à excelente constituição química do solo em que foi instalado o experimento e que o $\mathrm{N}$ lançado nos diversos tratamentos tenha sido excessivo, não causando nenhuma reação na planta. 


\section{2 .3 - Peso de 1000 sementes}

Ds resultados do peso de 1000 sementes nas quatro épocas (Ouadro 11 ), mostram que os tratamentos diferiram quanto à uti lização dos níveis de nitrogênio. De um modo geral, constatou-se que a ausència de nitrogênio (A) foi o tratamento que produziu semente de menor peso e cive o tratamento $C$ (nível II), em que se empregou a quantidade de $20 \mathrm{~g} / \mathrm{m}^{2}$ foi a de maior peso.

Estes resultados, quando comparados com os dos testes de vigor, discordam dos obtidos por SHARPLES e KUEHL (1974):SMI TH et alii (1973): Scaife e Jones, Sharples, Smith, Welch e Little (citados por SOFFER e SMITH, 1974c), que trabalharam com sementes de alface.

Considerando-se os resultados obtidos e a bibliografia consultada. pode-se salientar que existe uma correlação positiva entre os diversos nÍveis de $N_{s}$ o peso das sementes e o vigor das plântulas. SOFFER e SMITH (1974c) encontraram essa mesma correlação em sementes de alface. No presente trabalho não se obteve esta correlação positiva entre niveis de $N$, peso das sementes e vigor das plântulas. Duas suposições se pode levantar, ou os testes de labora törío não foram capazes de detectar esta diferença, ou para esta cul tivar, o $N$ influiu apenas no peso das sementes, mas não no vigor.

De uma maneira geral, a literatura existente sobre o estudo da influência do vigor da semente sobre o desempenho das plân tulas, no campo: é discordante. 
Alguns autores observaram diferenças e outros não, ao estudarem o comportamento de plântulas originärias de sementes com diferentes níveis de vigor.

\section{3 - Anälise ouímica das Sementes}

Com relação à análise química das sementes, foi feita com o objetivo de fornecer uma informação adicional.

Como se pode verificar, a determinação de nitrogênio nos diversos tratamentos não afetou a composição deste elementolQua dro 14). Já para as determinaçöes de fósforo e potássio (Quadros 16 e 18), o tratamento $A$, não adição de nitrogênio, diferiu dos demais. Pressupõe-se que, em virtude do solo onde foi instalado o experimen to ser rico em N,.$K$, conforme se observa pelos resultados apresentados pelà análise química(quadro 1), o nitrogênio excessivo colocado, teve ação antagónica aos dois outros elementos ( $P$ e $K$ ), con cordando com AUSTIN e LONGDEN (1966) e HAWORTH et alii (1966), que obtiveram resultados semelhantes com beterraba.

\section{4 - Estudos de Campo}

\subsection{1 - Determinação da matëria seca das plantas}

No presente trabalho foram eviddenciadas diferenças en tre os diversos tratamentos e a determinação da matéria seca das mu. das (Quadro 19), concordando com os resultados abtidos por SOFFER e 
SMITH (1974b): SHARPLES \& KUEHL (1974) e SMITH et alii (1973).

\subsection{2 - Determinação do peso da matëria fresca das plantas}

Quanto à determinação do peso da matéria fresca das plantas (Tuadro 20), a influência do vigor da semente somente foí. observada na sementeira. Com poucos dias de transplantadas não se percebia mais diferenças entre os diversos tratamentos, concordando com os resultados obtidos por SOFFER e SMITH (1974b), e discordando dos resultados obtidos por SCAIFE e JONES (1970). Enquanto as mudas se nutriam de suas próprias reservas, percebia-se diferenças bemmar cantes entre os tratamentos. Logo que foram transplantadas, possivelmente por passar a se manter dos nutrientes existentes no solo, esta diferença entre os tratamentos deixou de existir.

o presente trabalho é a primeira tentativa de se estudar a influêncla da adubação nitrogenada das plantas sobre a produção e qualidade de sementes de alface, em nosso meio. Os resultados aqui alcançados sugerem que se deva dar continuidade à pesquisa. havendo portanto: possibilidades de obtenção de resultados promisso. res para a melhoria da qualidade das sementes dessa composta. 
46.

\section{CORCLUSOES}

Dos estudos realizados nas condições do experimento e a interpretação dos resultados obtidos, pode-se concluir que:

a) a adubação nitrogenada não afetou a produção e a qualidade das sementes de alface (Lactuca sativa L.):

b) os testes de laboratório não foram totalmente satisfatōrios para avaliar a não influência da adubação nitrogenada sobre a qualidade das sementes de alface (Lactuca sativa L.);

c) houve ume correlação positiva entre os níveis de nitrogênio e o peso das sementes, com exceção do tratamento $D$ (nível III ] :

d) inicialmente houve diferenças no desenvolvimento das mudas das diversos tratamentos; 
e) Os sementes da cultivar Gorga não apresentaram dormenncia lo go apös a sua colheita. 


\section{B. SUMAMRY}

The present work was conducted in the experimental area and seed laboratory of Agriculture and Horticulture Department of Escola Superior de Agricultura "Luiz de Mueiroz", Piracicaba,Bra zil, in order to study the effect of $N$ fertilization on production and quality of lettuce (Lactuca sativa L.) "Gorga" seed. The treat ments were $0,10,20$ and $40 \mathrm{~g} \mathrm{~N} /$ plant.

Seed were storaged in dry chamber $\left(23^{\circ} \mathrm{C}\right.$ and $35 \%$ RU during 7 months. During this period, it was done germination test, first counting of germination, emergency velocity, emergency percentage, one thousand seeds weight and water content, in 4 period of two months intervals.

In field trial, it was determined dry weight of 30 days seedlings and fresh weight of commercial plants. 
For the experiment conditions, it was concluded that:

a) $N$ fertilizer did not affected the seed production and quality.

b) laboratory tests were not totally satisfactory to avaliate the lettuce seed quality:

c) there was a positive correlation between $\mathrm{N}$ levels and seed weight but treatment $D$ (III level):

d) firstly there were differences in seedlings development with treatments;

e) Gor:ra's seeds did not have dormency just after harvesting. 
50.

\section{LITERATURA CITADA}

ALTEN, F。 e E. SCIULTE, 1942. The effect of fertilizers on the speed of germination of cereal grains. Ernahr Pflanze, 37: 13-21.1941. Apud Chem. Abstr., Columbus, 36: 6732. |Resumo|.

AUSTIN, R.E.。 1965. The influence of the phosphorus and nitrogen nutrition of pea plants on the growth of their progeny. Plant. 8 Soil, The Hague, 24(3): 359-368.

AUSTIN, R.B. e P.C. LONGDEN, 1965. Effects of nutritional treatments of seed bearing plants on the performance of their progeny. Nature, London, 205: 819-820.

AUSTIN, R.E. e P.C. LONGDEN, 1966. The eifects of manurial treatments on the yield and quality of carrot seed. J. hort. Sci.. London, 41(4): 361-370.

EACCHI, O., 1960. Estudos sobre a conservação de sementes. V. Alface. Bragantia, Campinas, 19: 41-45. 
BRAY:CO, A.A. e F.A.A. CNUTO, 1962. Observaçöes sobre o efeito do azoto. fósforo a potássio na adubação de alface. Olericultura, Viçosa: 2: 88-96.

BRASIL. Ministērio da Agricultura. Equipe Técnica de Sementes e Mudas, 1967. Reguras para análise de sementes. Rio de Janeiro, ABCAR. $120 \mathrm{p}$.

CAMARGO, C.P. e C. VECCHI, 1971. Pesquisa em tecnologia de sementes. (Apresentado ao I Encontro Nacional de Técnicas em Análise de Sementes, Porto Alegre, RS . $45 \mathrm{p}$.

CAMARGO, C.P. e C. VECCHI, 1973. Vigor, presente no futuro? (Apre sentado ao IV Seminário Prasileiro de Sementes, Fortaleza, Ceaгӓ). 19 . .

CAMPOS, J.P.: F.A.A. COUTO e V.W.D. CASALI, 1975. Efeito de níveis e modo de aplicação de fertilizantes na germinação de sementes de quiabo. Revista Ceres, Viçosa, 22(121): 187-193.

DELOUCHE, J.C., 1971. Determinants of seed quality. In: Short Course for Seedsmen, State College, Mis. Proceedings. p. 53-68.

DELOUCHE, J.C., 1972. The compensation principle. Seedsmen's Dig., San Antonio, 23(1): 6, 49 .

DELOUCHE, J.C. \& H.C. POTTS, 1974. Programa de sementes; planejamento e implantação. Brasilia, AGIPLAN. $118 \mathrm{p}$.

EGUCHI, T., 1960. Influence of nitrogenous fertilizer applied at different stages of growth on seed production in cabbage and chinese cabbage. Proc. Am. Soc. hort. Sci., St. Joseph, 76: $425-435$. 
FILGUEIRA, F.A.R., 1972. Manual de Olericultura. São Paulo. Ed.Ce res. $451 \mathrm{P}$.

GILL, H.S.; P.C. THAKUR e B.S. BHULLAR, 1975. Effect of nitrogen and phosphorus fertilization on seed yield of late cauliflower. (Brassica Oleracea Var. botrytis). Indian J. Hort., Bangalore, $32(1 / 2): 94-97$.

HAWTHORN, L。R。, 1952. Interrelations of soil moisture, nitrogen, and spacing in carrot seed production. Proc. Am. Soc. hort.Sci., St. Joseph, 60: 321-326.

HARRINGTON, J.F., 1960. Germination of seeds from carrot, lettuce and pepper plants grown under severe nutrient deficiencies. Hilgardia, Berkeley, 30(7): 217-235.

HAWORTH, F.: T.J. CLEAVER E J.M. BRAY, 1966. The effects of different manurial treatments on the yield and mineral composition of red beet. J. hort. Sci., London, 41: 243-255.

KNOTT, J.E., 1957. Handbook for vegetable growers. New York, John Wiley. $238 \mathrm{p}$.

KOSAR, W.F. e R.C. THOMPSON, 1957. Influence of storage humidity on dormancy and longevity of lettuce seed. Proc. Am. Soc. hort. Sci... St. Joseph, 70: 273-276.

KOZLOWSKI, T.T., 1971. Growth and development of trees. New York. Academic Press. V. 2.

MAGUIRE, J.D., 1962. Speed of germination-aid in selection and evaluation for seedling emergence and vigor. Crop. Sci., Madison, 2(2): $176-177$. 
PIMENTEL GOMES, F., 1970. Curso de estatistica experimental. 4a. ed. Piracicaba, ESALq/USP. $430 \mathrm{p}$.

POPINIGIS, F., 1974. Fisiologia de sementes. Brasilia, Ministërio da Agricultura/AGIPLAN. $78 \mathrm{p}$.

RANZANI, G.: 0. FREIRE e T. KINJO, 1966. Carta de solos do Município de Piracicaba. Piracicaba, ESALQ/Centro de Estudos de Solos. $85 \mathrm{P}$.

REISENAUER, H.M.: J. QUICK e R.E. VOSS, 1976. Soil testing interpretative guides. In: REISENAUER, H.M., ed. Soil and plant tissue testing in California. Bull. Division of Agric. Sciences, ก. $1879: 38-40$.

SARRUGE, J.R. e H.P. HAAG, 1974. Anālises químicas em plantas. Piracicaba ESALQ/Departamento de Química. $56 \mathrm{p}$.

SCAIFE, M.A. e D. JONES, 1970. Effect of seed weight on lettuce growth. J. hort. Sci., London, 45: 299-302.

SHARPLES, G.C. e R.O. KUEHL, 1974. Lettuce seed weight and size in relation to germination and seedling radicle growth. Hortscience, St. Joseph, $\underline{9}(6): 582-584$.

SIMÃo, S., 1960. Adubação da Alface. Revista de Agricultura, Píra cicaba, $35(2): 149-154$.

SMITH, O.E. N.C. WELCH e O.D. MCCOY, 1973. Studies on lettuce seed quality: II. Relationship of seed vigor to emergence, seedling weight and yield. J.Am. Soc. hort. Sci.. St. Joseph, 98(6): $552-553$. 